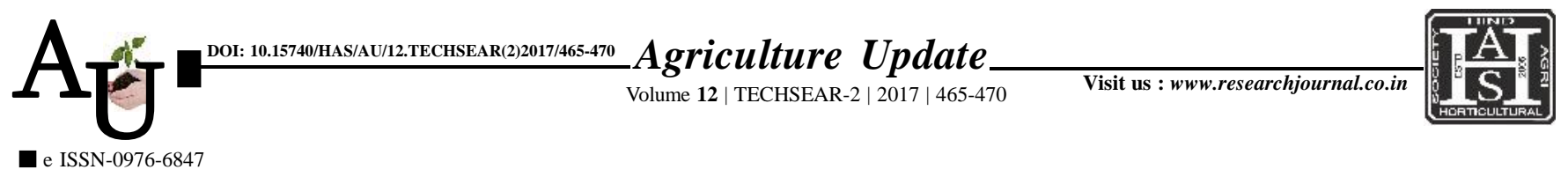

\title{
Research Article: Survey, morphological identification and effect of culture media on the growth of Lasiodiplodia theobromae causing die back disease in acid lime
}

\section{A. BHARANI DEEPAN AND E.G. EBENEZAR}

Article Chronicle: Received :

11.07.2017;

Accepted :

24.07.2017

KEY Words:

Acid lime, Die back,

Lasiodiplodia

theobromae,

Morphology,

Culture media

Author for correspondence :

\section{A.BHARANI DEEPAN}

Department of Plant

Pathology, CPPS, Tamil

Nadu Agricultural

University, COIMBATORE

(T.N.) INDIA

Email:bharanideepan 10

@ gmail.com

See end of the article for

authors' affiliations
SUMMARY : The die back disease of acid lime caused by Lasiodiplodia theobromae is a serious disease that causes severe yield loss. Hence, attempts were made to assess the incidence of the disease by survey in Tirunelveli and Thoothukudi districts. The survey report revealed that the die back of acid lime disease incidence ranged from 46.55 to 64.42 per cent. The mycelium of $L$. theobromae were hyaline, fast spreading, immersed, branched and septate and black coloured pycnidia were produced on the PDA medium. Conidia were initially hyaline, unicellular and ellipsoidal with granular content. Matured conidia were bi celled, thick walled dark brown in colour and it possessed longitudinal striations. Among the growth media tested, potato dextrose agar medium $(90.00 \mathrm{~mm})$ supported the highest mycelial growth followed by beetroot dextrose agar and nutrient agar medium $(79.00 \mathrm{~mm})$. The colony spreading rate was also found to be higher with the potato dextrose agar medium. While the King's B agar medium recorded the minimum mycelial growth $(47.00 \mathrm{~mm})$.

How to cite this article : Deepan, A. Bharani and Ebenezar, E.G. (2017). Survey, morphological identification and effect of culture media on the growth of Lasiodiplodia theobromae causing die back disease in acid lime. Agric. Update, 12(TECHSEAR-2) : 465-470; DOI: 10.15740/HAS/AU/12.TECHSEAR(2)2017/465-470. 